\title{
The Influence of Blue Ocean Strategy on Organizational Performance
}

\author{
Md. Habibur Rahman ${ }^{*}$, Sabbrina Choudhury ${ }^{2}$ \\ ${ }^{1}$ Lecturer, Institute of Agribusiness and Development Studies, Bangladesh Agricultural University, Mymensingh, BANGLADESH \\ ${ }^{2}$ Lecturer, Department of Business Administration, BGMEA University of Fashion and Technology, Dhaka, BANGLADESH \\ *Corresponding Contact: \\ Email: habib_du32@yahoo.com
}

Manuscript Received: 30 Sept 2019 - Revised: 10 Dec 2019 - Accepted: 21 Dec 2019

\begin{abstract}
The study deals with the blue ocean strategy (BOS) that offers users a framework for making uncontested market space and diverts the outlooks from the existing competition to the creation of innovative value and demand. The purpose of the study is to determine the influence of BOS on organizational performance. In this study, we systematically examine previous research on these topics of BOS. The findings show that there is a significant contribution of BOS to the enhancement of organizational performance. The study recommends that the policymakers should perform a critical analysis of BOS before implementation to see its suitability in the desired organization. Additionally, we identify future research areas that provide scholars opportunities to push theoretical boundaries and offer further insights into the study of BOS.
\end{abstract}

Key Words: blue ocean strategy, red ocean strategy, organizational performance, creative competition

JEL Classification Codes: M31, L25

\section{INTRODUCTION}

In the light of business developments, marked by rapid and dynamic transformations and complexity in different areas, new ways and methods will sustain competitive advantage. Because of the specific business conditions in today's world and the ever-changing environmental variables, we cannot freeze many data yet again and take action on future longterm plans (Chan, 2011). Strategic thinking has focused mainly on competitive approaches in the last twenty - five years, and competition issues have been at the core of policy growth trends. With such a behavior, it is no wonder that organizations, competently, learn how to compete and adopt a strategical stance, such as differentiation, cost reduction, or focus, through an analysis of the values of the economy (Eskandari, Miri, \& Allahyary, 2015).

One of the most significant innovations in strategic management, which has contributed to the creation of a revolution in this sector, is the BOS which has adopted measures to provide 
a range of particular instruments and methods to achieve the organization's strategic objectives. The BOS is the question of being meaningless of competition by finding new spaces for companies. In the past, however, to some degree, finding small markets at traditional economies was like this concept (where market share competition was restricted), but with this distinction, you do not have to restrict your target industry and clients in the Blue Ocean approach, but you are also focusing on creating valuably innovative technologies and entering fresh regions (Tavallaee, 2010). Kim and Mauborgne have offered the BOS with the focus on competition avoidance and the development of these valuable innovations that lead to lower costs and increased customer value (Chang, 2010).

The contemporary ideas of organizations strategic, working, and service fields are similar to two continents: the Blue Oceans and the Red Oceans. Indeed, the Red Oceans are renowned to all sectors and facilities and symbols in which they are competing today and organizations. On the other side, Blue Ocean is unknown space for different company sectors and is symbolic of all presently non-existent areas. Nowadays, an approach that will guide the organization to the Blue Ocean is not traditional approaches, such as item growth and facilities (including metropolitan growth, policing facilities etc.), discrete variations, working and service growth scopes, work and facilities intrusions, involvement, price decrease and transfer. It represents a valuable innovation as an approach that will generate more value for stakeholders about reducing expenses by implementing it (Eskandari, Miri, \& Allahyary, 2015).

Based on these arguments, the objective of this study is to explore the effect of BOS on the enhancement of organizational performance. The secondary data has been used throughout this research paper to meet this objective. For this reason, we systematically examine previous research on these topics of BOS. This research paper contributes to the literature on BOS by exploring the impact of BOS on organizational performance. From the practical point of view, the overall findings of the study may contribute to expanding the adoption of BOS in the organization. This research also contributes to the theoretical basis for further studies on BOS.

The research paper is structured as follows. Section 2 and 3 includes objectives and methodology of the study, respectively. Section 4 includes a review of the literature on BOS. Section 5 describes the pros and cons of BOS. Section 6 includes examples of applying BOS in the organization. Section 7 includes the implementation process of BOS. Section 8 includes the critics of BOS. Section 9 includes a discussion of the overall findings of the study. Section 10 presents some recommendations for successful implementation of BOS. Finally, section 11 concludes the paper by describing the implications and limitations of the study, and by suggesting future research directions.

\section{Objectives of the Study}

The objective of this study is to identify the role of BOS in increasing organizational performance. More specifically this study has two purposes: to determine the effect on the organization's results of BOS execution and thus demonstrate the significance of the application of this fresh market strategy; to give a clear idea about BOS including its scopes and limitations.

\section{Research Methodology}

This research paper is based on an extensive review of published and unpublished data/ information on BOS. Articles and research papers published in scientific journals were also reviewed. In a word, it is a review research paper based on secondary data. However, the research paper is based on reviews of English language research papers and reports. 


\section{LITERATURE REVIEW}

The higher authority of the organizations is transforming their policy to sustain in the competitive business world. Last few years, the number of desired structure of the strategy has been changed and for this, new model of the business named blue ocean strategy (BOS) proposed by Kim and Mauborgne (2004a), BOS is a theory which gives permission to think and invent innovation for their future business and help the company supporting by financial, economic-segments. The BOS describes the success issue for the pattern of organization is 'making the completion irrelevant'. From traditional competitive theories, it is a Reconstructionist view (Vinayan et al., 2012). When opponents also engage in 'bloody' competitive strategies, innovation reverts to energy waste (Kim \& Mauborgne, 2005b), as the competition among players lowers profits in differentiation or value of competition. Companies should seek to create new demand in open market space (blue oceans) rather than conflicting head-to-head in an existing (red oceans) industry. The strategy canvas is an instrument that can be used by organizations to discover a blue sea for their company. When establishing the strategy canvas, customers should seek to eliminate or reduce things that place little or no value on them, raise factors that highly enhance the value of customers, to add new factors that customers would like but presently provided by the industry (Kim \& Mauborgne, 2005a).

Kim and Mauborgne (2004a) indicate that demand is generated in the blue oceans instead of being fought. There are plenty of prospects for both profitable and rapid growth. BOS creates demands, and it avoids rivalry by pursuing particular organizational achievement patterns (Kim \& Mauborgne, 2005a). In their papers on the BOS, Kim and Mauborgne (2004a) stated that companies must stop to compete with each other. At the present technological stages, the reason for this is that market spaces are shrinking, and supply is exceeding demand due to globalization. More and more organizations are joining the existing markets, competition is made to lower the cost base with falling prices, but there can be no long-term answer to price rivalry (Kim \& Mauborgne, 2004a). Kim and Mauborgne (2004a) show that by searching and entering new and uncontested markets, organizations must not only outplay their competition but also totally disregard them. Therefore, the primary objective is to figure out what customers are looking for when they purchase an item or service and then identify a complete solution. Furthermore, the process of creating and discovering the blue ocean industry does not involve anticipating and pre-assigning company patterns. It's about top managers who can restructure the realities of the market in a profoundly new way.

The first theory that led to the BOS was the value innovation for high growth strategic logic in 1997. With new customer bases, no competition and new value creations, the Blue Oceans stand for totally new and undiscovered markets and opportunities. Demand is created, growth is profitable and fast, competition is irrelevant, game rules are not set, broad market space potential that has not yet been precisely explored. In terms of lucrative development and endless, the Blue Ocean is profound, and strong (Kim \& Mauborgne, 2005b). Focusing on building competitive advantages is detrimental to reshaping old industries, driving young industries to new frontiers, and building completely new industries. To achieve strong development, organizations need to run away from this cruel process of competitive benchmarking, imitation, and competition. Instead of pursuing value innovation, differentiation, and low price are concurrently followed organically (Kim \& Mauborgne, 2005b).

The simplest way to defeat the competition is to avoid attempting to remedy the competition. The limits of the sector are described and adopted in the Red Ocean, and the game's competitive rules are established. In Blue Ocean, competition is meaningless due to the 
fact the rules of the game are waiting to be established. The organizations trapped in the Red Ocean adopt a conventional approach, racing to overcome the contest by creating an unconquerable place in the present order of the sector. Surprisingly, Blue Ocean's designers have not used the contest as their standard. They concentrate on making the rivalry meaningless by generating a value leap for consumers and therefore, their organizations, thus opening up new and unquestioned market space (Halligan, 2006). The point is not that these policies are incorrect when it comes to Red Ocean Strategies, but that they are the policies that everyone uses. Without finding an approach that provides them a wide-open blue ocean ahead (Moon, 2014), nobody can stand out. Organizations experience a severe challenge in implementing BOS that involves four hurdles of cognitive, limited resources, motivation, and politics (Wallace, Castaneda, \& McGregor, 2009). Execution \& interaction should also be the cornerstone of a successful approach. Three simple measures are used in BOS to gage strategies that are the focus, divergence, and compelling tagline (Canopus Business Management Group, 2016). BOS encourages and performs business ideas and collective design from pioneers, migrants, and settlers to create new value and eliminate unproductive outsourcing (Rosales, 2010).

Kim and Mauborgne (2004b) declared expected threats and ways of acting on them when the BOS Principles used properly. They indicated that efficient strategies for the Blue Ocean should be about reducing danger rather than accepting risk. To change the strategy of the organization according to the BOS model, an organization must not only change its focus from competition to new opportunities but also attach great importance to current noncustomers. Benchmarking the competition is not an option to achieve value and cost approach for strategic focus reorientation, as this would result in the predictable competition. Historically, Blue Ocean's birth dates back to the milestone accomplishment of Cirque du Soleil, a circus business Canadian company. Cirque du Soleil's BOS formation pursued requirements for alternative types of amusement, ranging from multiple types of live urban entertainment to sporting activities, to an increasingly long shadow casting home entertainment.

Kim and Mauborgne (2005a) reveal that children's demand for play stations rather than a visit to the traveling circus has led to a steady decline in audiences at Cirque du Soleil and, in turn, falling revenue and profits have brought incredible achievement to Cirque du Soleil. What makes growth extraordinary is that it has been accomplished in a decreasing sector where the traditional strategic assessment has indicated restricted growth capacity. Another compelling aspect of the success of Cirque du Soleil is that it didn't succeed by taking customers from the already shrinking circus industry, which has catered to children historically. Ringling Bros. and Barnum \& Bailey didn't compete with it. Instead, it developed an uncontested fresh business room that rendered it meaningless to rivalry. It appealed to a whole fresh community of customer-adults, and commercial customers willing to pay the cost for an unprecedented entertainment experience several times as big as traditional circuses. The result of this is that each business can find distinctive methods to discover fresh business room using the BOS. It is also important to note that all companies have in common that they need to focus on noncustomers and also that most blue markets are often created within the existing red oceans (Kabukin, 2014).

Create a fresh industry in which there is no competitor and make rivalry pointless; this is exactly what BOS means (Buisson \& Silberzahn, 2010). Blue oceans, on the other hand, are those sectors that have not yet been established, those that are not presently exiting. Blue Ocean is a place in which there is no competitor (totally new market); therefore, this 
environment is a place with a high potential to generate lucrative and profitable returns for those companies that create it. We should also consider that this market does not have a competitive environment (Burke et al., 2009). Brady (2005) states that the BOS is developed based on quality developments. These are measures that slow down expenses while speeding up the importance for consumers at the same time. As the scale of business increases, the company can decrease expenses. Other features of the BOS are: creating uncontested market space, rendering the competition irrelevant, creating and capturing new demand, and breaking the value-cost tradeoff. Overall, the organization's use of the BOS to enforce success has experienced flow in recent years due in part to daily disruptive technologies. Kim and Mauborgne (2004b) suggest that value innovation is the foundation on which Blue Ocean is built to bring satisfaction to customers. By value innovation, Blue Ocean builds the unquestioned market space. Value Innovation is not about fighting for market share with other organizations but is discovering new markets and innovating values for both clients and the organization itself (Kim \& Mauborgne, 2005b; Randall, 2015).

Kim and Mauborgne (2005b) stated that eliminate, reduce, create, and raise are four measures to create value innovation for clients and organizations. Comparatively, in the current red ocean strategy (ROS) industry, the rivalry is concentrated (Borgianni et al., 2012; Leavy, 2005). BOS has six values for any company to formulate and execute. Such as 1 . Reconstruct the limits of the industry, 2. Focus not on numbers in the big picture, 3 . Reach beyond current demand 4 . Right the strategic sequence, while two are principles of execution. 5. Overcome main hurdles in the organization, 6. Build a strategy for execution. Organizations compete and leave behind their rivals to increase market demand (Kim \& Mauborgne, 2005a). Red oceans will always exist, and matter, but Blue oceans have to be created for high performance (Kim \& Mauborgne, 2005a; Hollensen, 2013).

Many latest surveys on empirical research, assessment instruments, and other elements of Blue Ocean policies (Borgianni et al., 2012) have been conducted that indicate the significance of this approach. It is possible to summarize five fundamental components or dimensions of the BOS as stated (Omar \& Tasmin, 2015) and modified from (Kim \& Mauborgne, 2005a) as; 1. Creating unchallenged market space 2. Making it irrelevant to competition 3. Creation and capture of new demand 4. Breaking the trade-offs of value-cost. 5. Achieving differentiation \& low cost. The BOS helps satisfy existing customers but also reach previous non-customers (Uzoamaka, Adaeze, \& Jude, 2018). Kim and Mauborgne (2005b) show that the BOS is helping organizations to innovate and create new products, thus gaining greater market share.

Noticeably, there are few studies related to the idea of generating or developing new markets. Other studies found solutions in their papers how organizations can generate new market space (Navis \& Glynn, 2010) remotely in comparison with BOS that also provides frameworks for making uncontested market space. It is also notable that few studies were performed to examine the influence of BOS on organizational performance. As per the above literature review, the objective of the study is to fill the identified gap by examining the influence of BOS on organizational performance and hence, the following research question is developed in this study.

- What is the influence of BOS on organizational performance?

The study will be laid out reviewing the organizations which attained successes implementing BOS to explore the actual influence of BOS on organizational performance. 


\section{The Pros and Cons of Blue Ocean Strategy}

\section{Blue Ocean Strategy}

The concept of BOS was launched in 2004 by W. Chan Kim and Renee Mauborgne in the publications of papers and well-sold books (2005) in more than 3.5 million countries and released in a 43 language record which has also been named a top 10 company book by amazon.com in 2005. This book is built on a research of more than 100 years and 30 sectors in 150 strategic movements. It provides analytical frameworks and tools for building and entering into new market areas based on commentaries by the authors. After BOS, every company will find unparalleled ways to discover new market space. However, it is essential for all businesses to remember that they must concentrate on non-customers and also be aware that most black markets are often produced within current red seas (Kim \& Mauborgne, 2004a). The BOS can merge the benefit of a single distinctive item with the competitive benefits in the two distinct industries already in operation (Hollensen, 2013). Kim \& Mauborgne (2004b), based on their research, created their BOS system which offers a set of instruments and frameworks that guide businesses in creating their own uncontested economies.

\section{Differences between Red Ocean and Blue Ocean Strategy}

There are primarily two kinds of approaches-Red Ocean (structural) and Blue Ocean (reconstructionist), between which economic attractiveness, the capacities of the organizations, and whether it has a strategic direction for competition or innovation-that must be suited. The structural approach calls for a low-cost or differentiated approach to individuals, importance and profit when reconstructionist addresses both (Kim \& Mauborgne, 2005a). It is further supposed that the Red Ocean is the traditionally overcrowded renowned marketplace where business is at a particular boundary, and there is a strategic match scheme for firms that compete to outperform market demand competitors that restrict elevated output and make a red ocean growing competition, and In contrast, the Blue Ocean is an unexplored market arena in which there is an undisputed market space without rivaling or making competition irrelevant, and without the traditional industry borders creating a new industry in the existing non-red ocean industries that is a notion that it is in deep waters.

For businesses, the BOS provides a range of possibilities for profitable fast development. Whether businesses know the reality, since previous days, BOS has always had a huge implementation in company. Both approaches have coexisted and will continue to exist (Kim \& Mauborgne, 2005a). The BOS is the strategy to value creation and exploration of non-clients generating a canvas of a company system with a full picture of reliable variables for alignment. In addition to developing an empathy map, the non-customers of this fresh industry can be separated in a business model canvas in order to obtain a more thorough understanding (Berry, 2015). It concurrently pursues differentiation and low price and stresses development for both fresh entrants and fresh entrants. It decreases expenses while simultaneously increasing the importance of customers. It is visually created, so that the collective wisdom of businesses can be efficiently executed (Hollensen, 2013).

BOS features consist of the traditional manner to achieve organizational efficiency by means of strong current rivalry, defeat competitors, take advantage of current requirements, trade value or price, and harmonize operation of the company with its strategic low-cost and differentiated selection (Kim, 2010). But, while BOS has powerful emphasis on organization, divisions, imperative tagline, the creation of undisputed marketplace, the irrelevance of rivalry, the creation of fresh demands and seizing of fresh supply, the breakdown of value or the trade in costs, and the harmonization of the whole scheme of organization's functions (Kim \& Mauborgne, 2005a). 


\section{Examples of Applying Blue Ocean Strategy in Organization}

The Blue Ocean Paradox, as revealed by Kim and Mauborgne in 2005, is thought to be the best way to understand BOS's appeal. The study found that just $14 \%$ of all the business start-ups studied were carried out on the Blue Ocean markets, but these $14 \%$ had a revenue impact of $38 \%$ and a profit impact of some $62 \%$ compared to the majority of $86 \%$ of red oceans launches, which achieved a profit impact of 39\% (Kim \& Mauborgne, 2004a). This paradox is very important for entrepreneurs who are always searching for ways to boost income and profits. There should be no competition for the existing companies. There should be no longer any competition from existing companies. The cause of this is that the market is shrinking, while supply, due to globalization, is overcoming demand. More enterprises enter existing markets, which means that the cost base can be reduced to a minimum and price drops, but the long-term solution cannot be competitive (Kim \& Mauborgne, 2004b). More surveys indicate that if stocks are saturated or declining, the BOS is most efficient. That is why a company is expected to focus on new groups of customers to improve its customer base (Hollensen, 2013). Kim and Mauborgne (2004a) stress that these firms must not only outplay their own competition, but also totally ignore them by searching for and entering new markets that are not contested. Kim and Mauborgne (2004a) developed their BOS model, which gives companies a series of tools and framework to develop unique strategies for the creation and creation of their own markets. The BOS has successfully been implemented by organizations such as Singapore's Value Innovation Action Tank (VIAT), IKEA Furniture Industry, Starbucks and Philips, which showed good corporate performance (Basri, Ghadzali, \& Ismail, 2011). Below are some real-world examples of successful BOS implementation:

\section{Yellow Tail}

Yellow Tail, another perfect example of the strategy of blue oceans is developing a new wine brand from Casella Wines. It's also a case study that shows the success of the Blue Ocean Strategy: Yellow Tail became the fastest increasing wine brand in the US history within three years of joining the industry (Muckersie, 2019; Carton, 2017).

Yellow Tail acknowledged that the majority of wine companies are operating in a red ocean in which market share competition is ardent. They knew that they could generate a blue ocean and draw on a new customer by decreasing or eliminating the components which the sector was competing with and differentiating itself. The traditional emphasis on renowned wines and aging has been deserted by Yellow Tail. And they have dissected complicated terminology that can generally be intimidating for prospective clients on vintage bottles. The Yellow Tail drink was created instead, sweet enough to attract the masses of people, thus capturing demand of wine buffs from beer and drinkers. And by bringing only two kinds, one blue and one white, they created it easier to purchase. The result is history, as they claim (Muckersie, 2019).

\section{iTunes}

When iTunes came into the market, the problem of consumers' illegal downloading music in the recording industry was solved while at the same time addressing the demand for digital à la carte songs. The Blue Ocean strategy of iTunes has developed a completely different range of music sales which enables both performers and customers to purchase one song versus whole records. For years, ITunes has dominated this marketplace and is largely responsible for driving the growth of digital music (Muckersie, 2019; Neill, 2019).

\section{Apple}

Steve Jobs and Steve Wozniak founded this company in 1976. By market capitalization it is considered as the world's largest company. For nearly two decades, Apple focused on 
computer software systems, implementing a BOS until 2001 and launching the iPod music player, which revolutionized music listening (see figure 1) (Kabukin, 2014).
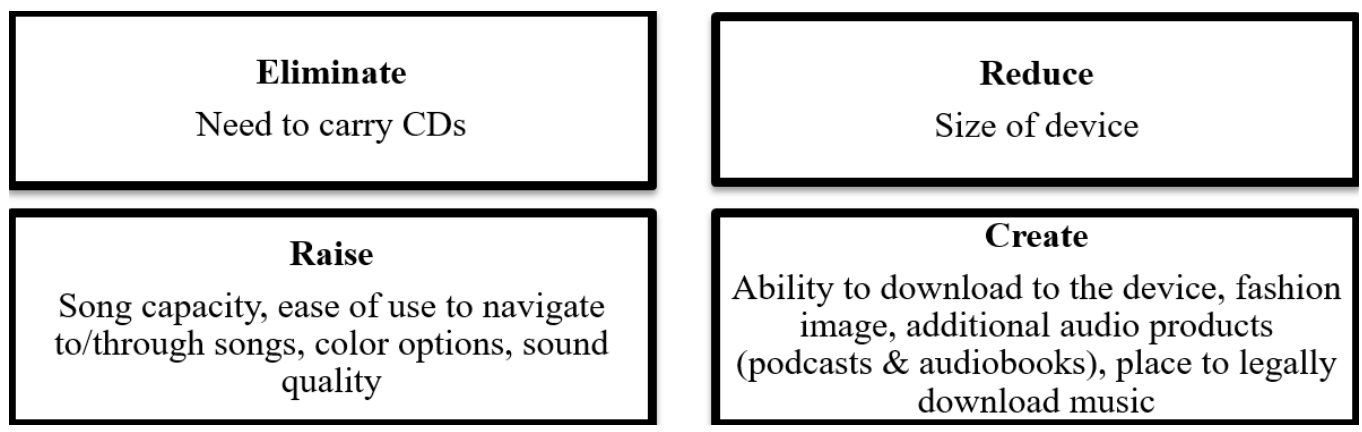

Figure 1: Product changes (iPad) using ERRC Grid (Kim \& Mauborgne, 2014)

The return on investment (ROI) for Apple was $28.6 \%$ per year from an investment of $\$ 3.3$ trillion (\$150 million for development and \$285 million for annual advertising, see source), and the profit was $\$ 52.5$ trillion (Apple had sold $€ 350$ million per unit as of September 2012, assuming that averages per unit $\$ 150$ million) (Kabukin, 2014).

\section{Backroads}

This company has made travel more complex and attractive than the typical relaxing route of the all-inclusive cruise or beach holiday. Backroads extended the sector into something new: active luxury transport. These fitness excursions are meticulously intended and include guides who bring visitors to walk, bike, camp and more. The Blue Ocean Strategy from Backroads attracted a much distinct public than vacationers who want to relax, and played a significant part in broadening the sector to include tourists who want to be satisfied and achieved at the end of their journey (Muckersie, 2019; Neill, 2019).

\section{Bloomberg}

Bloomberg was one of the world's biggest and most lucrative suppliers of company data in just over a century by the U.S.-based economic data supplier. Bloomberg established a blue ocean in the economic indicators services sector, challenging the conventional wisdom of its sector, which customer group was to aim at (Neill, 2019; Carton, 2017). Bloomberg was prepared to build an ocean of powerful, lucrative development by concentrating on customers. Bloomberg could also see with this change in focus the paradox of private life of traders and analysts. They have enormous income, but they work so long that they don't have much time to invest. Bloomberg has decided to add information and buy service to enhance traders ' personal lives, realizing that markets are slow during the day when little trade takes place. Earlier than the Internet, traders could purchase products such as flowers, apparel and jewelery using Bloomberg online facilities; create transport agreements; receive data about wines; or search for actual property lists (Neill, 2019).

\section{Netflix}

Marc Randolph and Reed Hastings established this business in 1997 in Silicon Valley. The company initially rented a website for paying film rental on which the film would be shipped to you and sent back to them. Netflix shifted to a monthly subscription model to ask to have your monthly premium in 1999 delivered an amount of videos. Sales started to increase and, with \$272 million and 6.5 million in revenue, the company's first profit in 2003 was achieved. In 2007, Netflix started to stream video online to allow users to see films on the internet. The 
use of the BOS has made it the world's film streaming service with revenues of $\$ 3.6$ trillion and profits of $\$ 17$ million in 2012 (see figure 2) (Kabukin, 2014).
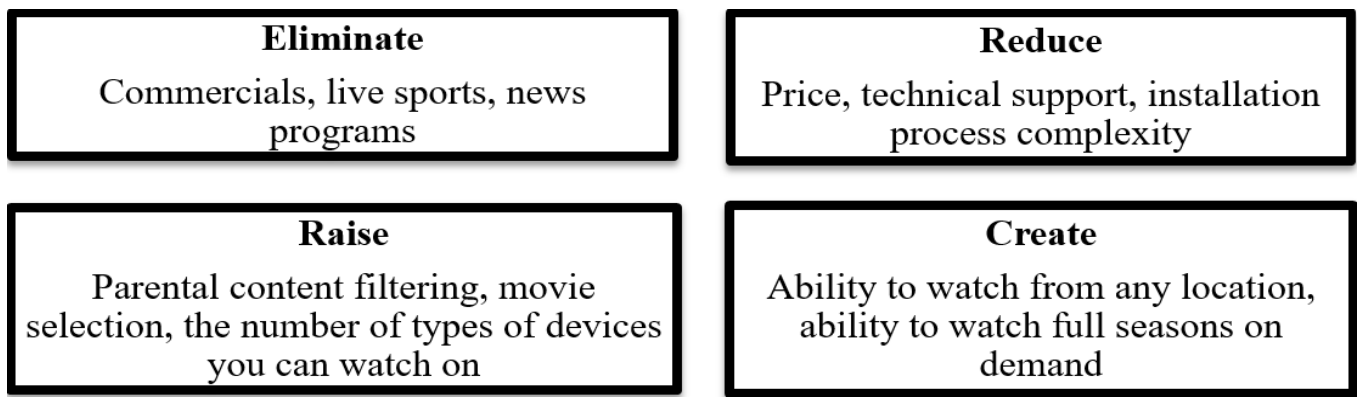

Figure 2: Product changes using ERRC Grid (Kim \& Mauborgne, 2014)

The Netflix gained ROI 114 percent annually as long as profits remain at 112 million dollars a year, most likely when investment amounted to 97.4 million dollars (2.5 million dollars (initial investment) plus 94.9 million dollars of stock offerings) (Kabukin, 2014).

\section{Canon}

The strategic movement of Canon, which created the personal copy industry, is a classic example of a strategy for the blue ocean. Traditional copy makers aimed office buying executives who wished big, lasting, quick and maintenance-requiring machines. In defiance of its industry logic, the Japanese Canon company created a blue sea of new market spaces by shifting the copier industry's target customers from company buyers to users. Canon developed fresh market room with its tiny, easy-to-use desktop copiers and printers by focusing on the competitive variables that were needed by many non-customers-secretaries using copiers (Neill, 2019; Carton, 2017).

\section{The Ford Model T}

Ford's Model T, launched in 1908, is a classic illustration of a strategic blue ocean market creation which has questioned car industry conventions in the United States. It opened the car to the mass of the economy. Until then, five hundred car makers in America constructed custom new cars. The sector was tiny, unattractive, with vehicles unreliable and costly at approximately $\$ 1.500$ twice the annual averages for the household despite the number of car manufacturers. But with Model T, Ford altered everything. Model T sales exploded. From 9\% in 1908 to $61 \%$ in 1921, the Ford business share peaked. The blue ocean was so large that Ford had developed Model T as the main transportation vehicle in the USA (Neill, 2019; Carton, 2017).

\section{Cirque du Soleil}

Guy Lailberte created the company in 1984. In the beginning in 1980 the group toured before they joined, performing as "The Wanderers." They had to face financial difficulties during those years and received government funding in 1983 to stay in flood. In 1984, their performance changed to one without animals that focused on a theatrical approach based on character (see figure 3). By employing the BOS, it became the world's biggest theater company with a turnover of over \$1 trillion each year in 2011(Kabukin, 2014).

Total ROI was earned by Cirque du Soleil at 35000\%, where revenue was 1.5 million dollars (from Canadian state to theatrical spectacle) and profit 175 million dollars / year (2008 estimate) estimating ROI per year of $21 \%$ (Kabukin, 2014). 


\section{Eliminate}

removed animals and star performers

\section{Raise}

increased prominence of acrobats, increased focus on visual performance (lights, timing of acts etc.), raised the level of comfort, elegance and sophistication of the venue

\section{Reduce}

reliance and variety of food and drink concessions

\section{Create}

added dancing numbers and musical theater, added multiple productions/shows giving people a reason to return

Figure 3: Product changes using ERRC Grid (Kim \& Mauborgne, 2014)

\section{Cemex}

One of the world's biggest cement manufacturers, Cemex developed an ocean that was historically competitive only with cost and features and had elevated profitability and development in the cement sector. This was done through the shift between the functional and emotional direction of its sector (Neill, 2019; Carton, 2017).

At its first appearance, the construction supplies club of Patrimonio Hoy that Cemex established comprised of around 70 individuals, who spent an average 70 nights contributing 120 pesos a week. However, the recipient did not obtain the amount of pesos, but rather the corresponding construction material for a whole fresh space. Cemex supplemented the profits by delivering the cement to the house of the winner, building workshops on how to construct efficiently spaces and a technical consultant who was involved in his venture with the respondents. Result: respondents in Patrimonio Hoy are three times quicker than the normal Mexican household building or modifications. While Cemex's rivals sold cement sacks, Cemex marketed a dream with an innovative funding and building expertise company model. Cemex took a step closer and launched tiny town festival when a house was completed thereby reinforcing people's happiness and the tanda tradition (Neill, 2019).

\section{The Nintendo Wii}

Founded in 1889, this company then produced handcrafted hanafuda cards. It is now the world's largest company in the field of video gaming. With the launch of the Nintendo Entertainment System in 1983, Nintenedo was able to try out many different companies before successful video games and revolutionized both the company and the industry.

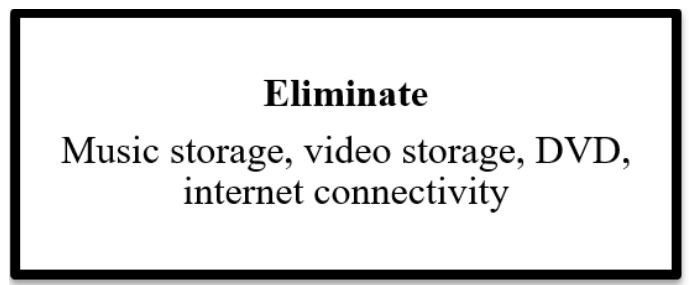

\section{Raise}

Number of family games, more internally developed games

\section{Reduce}

Development costs for video game producers (an average of $\$ 8$ million vs $\$ 20$ million), system sophistication, graphics, productions costs, retail price, processing power

\section{Create}

Games for the elderly, motion controllers

Figure 4: Product changes using ERRC Grid (Kim \& Mauborgne, 2014) 
In 2006, Nintendo introduced the Nintendo Wii, together with several advanced features of the revolutionary Wii system. The wireless remote control systems were the most notable among these. Nintendo also took a BOS focusing on targeting families (including seniors) rather than the young male hard core played by the industry during this time (see figure 4) (Kabukin, 2014). Nintendo Wii earned three-year ROI of $130 \%$ or $32 \%$ per year except for over 250 million Wii sales games that Nintendo has sold since launch, which amounts to $\$ 448$ million in investment (estimated at \$124 million for research and development and 394 million dollars for marketing expenditures) and $\$ 1,032$ Million for profit (estimated at $\$ 6-\$ 50$ per Wii console). 3 years of ROI inclusive of game sales found $800 \%$ or $108 \%$ yield (for $30 \%$ and average of $\$ 40$ contribution margins) (Kabukin, 2014).

\section{NetJets}

The blue ocean of partial jet property was built by NetJets. The NetJets today is a multimilliondollar corporation with the biggest personal jet fleet worldwide- more than seven hundred airplanes operating across one hundred and seventy nations. NetJets has noticed that business tourists, the most profitable group of clients in the aviation sector, have two main decisions (Neill, 2019; Carton, 2017). For generating a blue ocean, NetJets built on these unique strengths. As a consequence, the fractional jet possession fresh business room. Customers here are not purchasing an outright jet. They buy only a small portion of it. The outcome is a private jet at the cost of business airline journeys that is convenient for consumers. The use of larger national airports and restricted employees by NetJets' larger airplanes minimize expenses. No flight transfers occur with point-to-point services and a growing amount of airports to land. Tickets requiring overnight accommodation can be finished in one day. Your vehicle takes time to take off in minutes, not hours. Perhaps most interestingly, with only four hours ' notice, your jet is always accessible. NetJets will charter a jet for you if it is not accessible. NetJets dramatically decreases safety threats problems and provides tailored in-flight service to customers in particular (Neill, 2019).

\section{Critics of Blue Ocean Strategy}

The BOS includes excellent business ideas to sustain the organization in the competitive business world. But it is not free from criticism. A study by Herman (2008) found that the basic notion of BOS is not new and explained misleading customers and demand are not generated but taken from other markets, competition is always existent, no Blue Ocean markets can be generated, BOS doesn't attain precise results in the long term, the basic notion of BOS is described in a differentiation strategy, and the period of BOS success is the period of unfair advantage. Burke et al. (2009) found that the literature of BOS doesn't offer distinction between short term and long term strategic time horizons, the BOS absences in evidence, the rationality of BOS relies on inappropriate guesses and beliefs in sufficient Blue Ocean Markets, the vague definition of innovation existed in the BOS and the Blue Ocean Markets are rarely purely uncontested.

\section{FINDINGS}

The research has shown well the significance of the approach of the BOS in the competitive business world. Many companies today face global competition, advances in technology, traditional stuff, longer owners, which are essential today and are therefore requiring certain creative methods to invent precious customer services. Our study shows a significant influence of BOS on organizational performance. After adopting the BOS, the return on investment (ROI) for Apple was $28.6 \%$ per year from an investment of $\$ 3.3$ trillion, and the profit was $\$ 52.5$ trillion (Kabukin, 2014). The Netflix gained ROI 114 percent annually as long as profits remain at 112 million dollars a year, most likely when investment amounted to 97.4 million dollars (Kabukin, 2014). Total ROI was gained by Cirque du Soleil at 35000\%, where revenue was 1.5 million dollars and profit 175 million dollars / year (2008 estimate) estimating ROI per year of $21 \%$ (Kabukin, 2014). Nintendo Wii earned three-year ROI of $130 \%$ or $32 \%$ per year except for over 250 million Wii 
sales games that Nintendo has sold since launch, which amounts to $\$ 448$ million in investment and $\$ 1,032$ Million for profit. 3 years of ROI inclusive of game sales found $800 \%$ or $108 \%$ yield (Kabukin, 2014). Similarly, other organizations such as Yellow Tail, Backroads, iTunes, Bloomberg, Canon, The Ford Model T, Cemex, and NetJets have become successful implementing BOS.

The study also found that BOS can be applied in for-profit industries, non-profit industries, or the public sector. By reforming the industry boundaries, the BOS aims to make competition meaningless. Therefore, there is generated a new and uncontested market space of new demand and high profitable growth instead of being fought. It tries to break the value cost tradeoff by removing and reducing factors and, thus, facilitate the value innovation. The BOS shows the frameworks to break away from the competition and create a blue ocean of uncontested market space. By using BOS, managers get the exact ways to minimize risks and increase the opportunities to sustain the organization for the long term. It also makes the process non-intimidating and an effective path for facilitating execution into strategy and the collective wisdom of a company. It shows how to align the three strategy propositions- value, profit, and people to make sure that the organization is associated around the new strategy and it makes a win for buyers, the company and for stakeholders and employees. Therefore, it is very clear that the BOS is a basic approach to create new markets and demand concentrating on innovation.

\section{RECOMMENDATIONS}

Based on our study, suggested recommendations are as follows: While implementing the BOS, the organization should consider its risks and limitations. The management should create fresh thoughts and motivate staff to promote this. The organization must have the reliability and rationality to accept the BOS, making many arguable assumptions about how businesses presently function. Organizations need to reexamine the integrity of the analytical instrument that existed in the BOS, consult with company specialists to embrace the BOS, conduct Strengths, Weakness, Opportunity, Threats (SWOT) analysis to decide whether or not to embrace BOS, and lastly the BOS should again be justified for its excellent attraction in the current competitive company environment. To encourage entrepreneurs and business managers to develop innovative concepts and strategies, government and policymakers should try to build a more creative environment.

\section{IMPLICATIONS, LIMITATIONS, FUTURE RESEARCH AND CONCLUSION}

\section{Implications for research and practice}

Entrepreneurial and innovation activities are prioritized as one of the most important economic policies. The BOS forces the company to destroy the bloody competition of ROS with creating an uncompetitive market space. This new concept, instead of the dividing the demand among competitors, helps in growing demand in one hand and nullifies competition on the other hand. This research paper contributes to the literature on BOS by exploring the impact of BOS on organizational performance. The BOS is playing a vitally important role in creating a new and uncontested market space of new demand and high profitable growth. In this regard, researchers have a special research interest towards the various aspects of BOS. We do believe that this research advances the study of BOS that, in turn, will keep a significant contribution towards the theoretical basis for further studies on BOS.

This study also contributes to taking some new initiatives for the adoption of BOS in the organization. Here the details of BOS are discussed that can lead to getting some further development strategies to reduce its current limitations. The managers of the organizations can get a good idea about BOS. This mentioned benefits of BOS can lead the managers to take further steps to adopt BOS. From the practical point of view, the overall findings of the study may help the managers of the organization to know the details about BOS, in turn, can lead to generating some new steps for the development and expansion of their existing marketing strategy. The findings show that many renowned organizations have started implementing BOS for the development of 
the uncontested market and high profitable growth. In this regard, managers can implement BOS due to its vast economic importance. This study also helps identify some limitations regarding the BOS. So we do believe that this research will help the managers to be careful about these troubles existing in BOS. Based on our study, it can be said that the formation of the phenomenon of BOS is quite an accomplishment and dynamic process.

\section{Limitations and future research}

Limitations of the study show ways for future research prospects. This study was performed based on only secondary data. Future studies can be expanded to investigate the influence of BOS on organizational performance empirically. It will also be very interesting in future to empirically investigate the variables that reveal performance such as strategy, leadership, innovation and development, information technology, structure, quality, performance measurement, corporate governance, external environment and more where the rate of use of these factors completely balanced with the organizational performance (Gavrea, Ilieş, \& Stegerean, 2011).

\section{Conclusion}

The BOS is the backbone of organizational growth and sustainability; it forces the company to destroy the bloody competition of ROS by creating uncompetitive market space. The BOS is considered as the creation of a new, uncontested market space by organization given creating more customer satisfaction and enhancing profitability through market share. From our study, it is very clear that the BOS has a great influence to take the organization beyond the normal competition and make the organization a unique one. Instead of its great advantages, there are some disadvantages too. Therefore, the organization needs to perform a SWOT analysis and consult with the experts to evaluate the feasibility of implementing BOS so that the BOS can ensure long-term sustainability and the utmost success of the organization.

\section{REFERENCES}

Basri, J., Ghadzali, M., \& Ismail, M. (2011). BOS: Application in Universiti Sains Malaysia Library. Jurnal PPM, 5. Retrieved From Http:/ / Eprints.Usm.My /26112/1/Blue_Ocean_Strategy.Pdf

Berry, G. (2015). Why the Business Model Canvas Complements BOS. NHL Hogeschool.

Borgianni, Y., Cascini, G., \& Rotini, F. (2012). Investigating the patterns of value-oriented innovations in blue ocean strategy. International Journal of Innovation Science, 4(3), 123-142.

Brady, R. (2005). W. Chan Kim and Renee Mauborgne's Blue ocean strategy: How to create uncontested market space and make the competition irrelevant. Harvard Business Press.

Buisson, B. \& P. Silberzahn (2010). Blue Ocean or Fast-Second Innovation? A Four-Breakthrough Model to Explain Successful Market Domination. International Journal of Innovation Management, 14(03), $359-378$. DOI: $10.1142 / \mathrm{s} 1363919610002684$

Burke, A., Stel, A., \& Thurik, R. (2009). Blue Ocean versus Competitive Strategy: Theory and Evidence. Erim Report Series Research in Management. Retrieved from http:/ / hdl.handle.net/1765/16037

Canopus Business Management Group. (2016). Characteristics of a Good BOS. Collaborat.com. Retrieved from http:/ / www.collaborat.com/characteristics-of-a-good-blue-ocean-strategy/

Carton, G. (2017). A Blue Ocean Strategy for "Blue Ocean Strategy": on Performativity of Strategic Management. Academy Of Management Proceedings, 2017(1), 17635. doi: 10.5465/ambpp.2017.17635abstract

Chan, k. \& Mabourn, R. (2011). The Blue Ocean Strategy: How to create market space without resistance and unrelated to competition. (translated by: Atefi Mohammad Reza), Second edition, Tehran: Naab Publishing.

Chang, S. (2010). Bandit cellphones: A BOS [Abstract]. Technology in Society, 32(3), $219-223$. http:/ /dx.doi.org/10.1016/j.techsoc .2010.07.005

Eskandari, M., Miri, M., \& Allahyary, A. (2015). Thinking of the blue ocean - strategy beyond the competition. Asian Journal of Research in Business Economics and Management, 5(8), 134. DOI: 10.5958/2249-7307.2015.00166.8 
Gavrea, C., Ilieş, L., \& Stegerean, R. (2011). Determinants of Organizational Performance: The Case of Romania. Management \& Marketing Challenges for the Knowledge Society, 6(2), 285-300.

Halligan, B. (2006). BOS: A Small Business Case Study.

Herman, D. (2008). Marketing Article: The Limitations of Blue Oceans Strategies and an Unexpected Alternative. Marcommwise.com. Retrieved 14 July 2019, from http:/ / www.marcommwise.com/article.phtml?id=911

Hollensen, S. (2013). The Blue Ocean that disappeared-the case of Nintendo Wii. Journal of business strategy, 34(5), 25-35.

Kabukin, D. (2014). Reviewing the BOS. Is the BOS valid and reliable? (Master). The University of Twente.

Kim, W. \& Mauborgne R. (2004a). Blue Ocean Strategy. Harvard Business Review, 82 (10), 76-84.

Kim, W. \& Mauborgne, R. (2004b). Value innovation: The strategic logic of high growth. Harvard Business Review, 82(7-8), 172-180.

Kim, W. \& Mauborgne, R. (2005a). BOS: From Theory to Practice. California Management Review, 47(3), $105-121$. http:/ /dx.doi.org/10.2307/41166308.

Kim, W. \& Mauborgne, R. (2005b). Value innovation: a leap into the blue ocean. Journal of Business Strategy, 26(4), 22-28. http:/ /dx.doi.org/10.1108/02756660510608521.

Kim, W. \& Mauborgne, R. (2014). The Mind Map of Blue Ocean Leadership. INSEAD Knowledge. Retrieved 15 July 2019, from http://knowledge.insead.edu/leadership-management/the-mind-map-of-blue-oceanleadership-3690

Kim, W. (2010). How strategy shapes structure. Strategic Direction, 26(2).

Leavy, B. (2005). Value pioneering-how to discover your own "blue ocean": an interview with W. Chan Kim and Renee Mauborgne. Strategy E Leadership, 33(6), 13-20.

Moon, G. (2014). Want to Make Your Blog Stand Out? Use The BOS. CoSchedule Blog. Retrieved from http://coschedule.com/blog/blue-ocean-strategy/

Muckersie, E. (2019). 3 examples of blue ocean strategy - Decidedly. Retrieved 21 August 2019, from https://decidedly.com/3-examples-blue-ocean-strategy/

Navis, C. \& Glynn, M. (2010). How New Market Categories Emerge: Temporal Dynamics of Legitimacy, Identity, and Entrepreneurship in Satellite Radio, 1990-2005. Administrative Science Quarterly, 55(3), 439471. http:/ /dx.doi.org/10.2189/asqu .2010 .55.3.439

Neill, J. (2019). Blue Ocean Strategy Examples | Blue Ocean System. Retrieved 21 August 2019, from https://www.blueoceansys.com/blogs/blue-ocean-strategy-examples/

Omar, R. \& Tasmin, R. (2015). Society Transformation and Social Development through University-Community Transformation Centre (UCTC) Via Universiti Tun Hussein Onn Malaysia Experience. Journal of Techno Social, 7(2).

Randall, R. M. (2015). W. Chan Kim and Renée Mauborgne dispel blue ocean myths. Strategy E Leadership, 43(2), 11-14.

Rosales, R. (2010). BOS: A whole new world.

Tavallaee, R. (2010). The Blue Ocean Strategy, as revolutionary in the field of strategic management. Police Journal of Human Development, 24, $55-77$.

Uzoamaka, E., Adaeze, E., \& Jude Obinna, J. (2018). Effect of Blue Ocean Strategy on the Performance of Telecommunication Firms in South-East Nigeria. European Journal of Business and Management, 10(21), 48-56.

Vinayan, G., Jayashree, S., \& Marthandan, G. (2012). Critical success factors of sustainable competitive advantage: A study in Malaysian manufacturing industries. International Journal of Business and Management, 7(22), 29.

Wallace, C., Castaneda, M., \& McGregor, P. (2009). BOS: Overcome Key Organizational Hurdles.

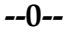

